ORIGINAL ARTICLE

\title{
Comparison of Endoscopic Sinus Surgery and Continued Medical Treatment Therapy for patients with Refractory Chronic Rhinosinusitis
}

\author{
SADAF RAFFAT ${ }^{1}$, MUSTAFA, NIGHAT ARIF², USMAN ASLAM ${ }^{3}$, M MUBARIK ALI $^{4}$, GULAM DASTAGIR KHAN ${ }^{5}$, JAVED \\ IQBAL 6 \\ ${ }^{1}$ Assistant Professor ENT, Islamic International Medical College, Lahore \\ ${ }^{2}$ Associate Professor ENT, Islamic International Medical College, Lahore \\ ${ }^{3}$ Assistant Professor, Avicenna Hospital, Medical and Dental College, Lahore \\ ${ }^{4}$ Associate Professor, Avicenna Hospital, Medical and Dental College, Lahore \\ ${ }^{5}$ Associate Professor, Sharif Medical City, Lahore \\ ${ }^{6} \mathrm{Head}$ of ENT Department, Al-Aleem Medical College, Gulab Devi Teaching Hospital, Lahore \\ Correspondence to Dr. Sadaf Raffat, Email: drsadafrafat@yahoo.com, Contact:0332-5105558
}

\begin{abstract}
Aim: To compare endoscopic sinus surgery and continued medical treatment in refractory refractory chronic rhinosinusitis (CRS) patients regarding diseases specific quality of life measurement

Study design: RCT (Randomized controlled trial)

Place and duration of study: Study was conducted at ENT (Ear, nose and throat) department, Railway Hospital Rawalpindi. Study duration was one year (January 2018-Deecember 2018)

Methods: A sample size of 22 patients was calculated using WHO calculator. Non probability consecutive sampling was used. A prior ethical approval and consent form was taken. Patients were randomly divided into two groups; Group A was given medical therapy while Group B comprised contain patients in whom medical therapy failed and had undergone endoscopic sinus surgery. Patients were followed for disease specific quality of life scores. Data was analyzed using SPSS version22. Chi-square and t test was applied. P value $\leq 0.05$ was considered significant.

Results: Total of 22 refractory CRS patients were included in study. There were 10(45.5\%) males and 12(54.5\%) females. Mean age of refractory CRS patients was 33.4 years $\pm 6.2 S D$. Group A (continued medical therapy) $\mathrm{N}=11$, had significantly high SNOTT -22 scores $60.6 \pm 7.1 S D$ as compared to endoscopic sinus surgery $21 \pm 3.9 S D$ $(p=0.000)$. Group B (endoscopic sinus surgery) had significantly low endoscopic scores $2.7 \pm 0.3 S D$ as compared to group A (continued medical therapy) 7.14 $\pm 0.53 S D(p=0.000)$. Endoscopic sinus surgery group showed significant reduction in work days lost $17.4 \pm 4.9 \mathrm{SD}$ as compared to continued medical therapy (Group A) $30.1 \pm 2.5 \mathrm{SD}$ $(p=0.000)$.

Conclusion: Endoscopic sinus surgery is an effective treatment option as compared to continued medical therapy with improved quality of life in refractory CRS patients (with reduced baseline disease specific quality of life).

Keywords: Refractory chronic rhinosinusitis, endoscopic sinus surgery, quality of life
\end{abstract}

\section{INTRODUCTION}

Chronic rhinosinusitis (CRS) is defined as inflammation of paranasal sinuses. An estimated 31 million Americans are affected with CRS annually ${ }^{1}$. Refractory chronic rhinosinusitis (RCRS) referred as persistent and poorly controlled symptoms of chronic rhinosinusitis with objective inflammation, despite prior medical and surgical treatment ${ }^{2}$. Prevalence of refractory CRS is $1-5 \%$ in United States. Incidence of refractory CRS in Europe is 9.6\%, North America $15.5 \%$ and in Asia ranges from $1.01 \%$ to $7.12 \%{ }^{3}$.

Pathophysiology of refractory CRS is defined as secondary to susceptible host interaction with environment (outside). Mucosal inflammation and bacterial load reduction are significantly associated with disease control ${ }^{4}$. Literature reported that inflammatory response to bacterial colonization had significant role in pathophysiology of refractory CRS. Refractory CRS is associated with comorbidities like asthma, cystic fibrosis, allergies, vasculitides, immunodeficiency syndrome and

Received on 22-04-2021

Accepted on 27-08-2021 granulomatous diseases ${ }^{5}$. According to American Academy of Otolaryngology (Head and neck surgery diagnostic criteria) diagnosis of refractory CRS is associated with four cardinal symptoms; i) nasal obstruction, ii) nasal drainage, iii) facial pain/pressure, iv) hyposmia/anosmia. Literature reported mucopurulent drainage, polyps in middle maeatus and edema on physical examination as objective evidence of refractory CRS diagnosis ${ }^{6}$.

Refractory CRS treatment aims to manage symptoms and improve quality of life in patients. Management strategy is concerned with mucociliary clearance enhancement, local infection eradication, sinus drainage improvement and topical medications access improvement ${ }^{7}$. Refractory CRS treatment is divided into two main categories; medical management and surgical management. Medical management include nasal saline irrigation, topical intranasal corticosteroids, antibiotics and oral corticosteroids. Surgical management is directed towards endoscopic sinus surgery ${ }^{8}$. Endoscopic sinus surgery is an effective treatment option when medical remedies are not effective in refractory CRS. Endoscopic sinus surgery has three major goals i) drainage of paranasal sinuses, ii) provision of ventilation, and iii) 
enlargement of paranasal sinuses for topical medicines access on large scale ${ }^{9}$.

A similar study reported that endoscopic sinus surgery is very effective in terms of mean follow up after surgery (14.6 months), Sino-Nasal outcome test SNOT scores 66 to 16 $(p<0.05)$, work days lost and medication consumption $(p<0.0001)^{10}$. Evidence exist that endoscopic sinus surgery had high efficacy for refractory CRS patients as compare to conventional medical treatment when compared in terms of disease specific quality of life scores ${ }^{11}$. Limited literature is available on efficacy of endoscopic sinus surgery in Pakistan.

Present study aims to compare efficacy of endoscopic sinus surgery and continued medical treatment in refractory CRS patients regarding diseases specific quality of life measurement.

\section{MATERIAL AND METHODS}

An Randomized controlled trial was conducted at ENT (Ear, nose and throat) Railway Hospital, Rawalpindi. Study duration was one year (January 2018-Deecember 2018). A sample size of 22 refractory CRS patients was calculated (11 patients in each group) through WHO calculator using $\mathrm{P} 1=66 \%$ and $\mathrm{P} 2=16 \%$ with confidence interval $95 \%$ and power of study $84 \%{ }^{12}$. Non probability consecutive sampling was performed. Ethical approval was taken from ethical review board of hospital. Consent was taken from all participants. Patients age $>18$ years, both genders and diagnosed with refractory CRS were included in study. Exclusion criteria was based on medical therapy contraindications, patients with cystic fibrosis, inflammatory disease (systemic) and ciliary dysmotility. Refractory CRS patients were randomly divided into two groups using computer generated random number table. Group A was given medical therapy (high volume saline irrigation for 3 months, topical intranasal steroids therapy for 7 days and broad spectrum antibiotics for at least 2 weeks). Group B patients included those patients who due to failed medical treatment underwent endoscopic sinus surgery. Before endoscopic sinus surgery was performed, patients were provided with prednisone (30mg once daily), amoxicillinclavulanic acid (875 $\mathrm{mg}$ twice daily) or trimethoprimsulfamethoxazole (twice daily) for at least 7 days. Post operative care included high volume isotonic saline sinonasal irrigation (one day after surgery), systemic antibiotics (for 7 days), sinosnasal debridement (at 1 and 3 weeks after surgery). Patients were followed after 3 months. Primary outcome was measured in terms of disease specific quality of life scores using sinonasal outcome test -22. However, secondary outcome was measured by endoscopic grading (Lund Kennedy standardized scoring system) and work days missed (last 90 days). Efficacy was determined in terms of mean reduction in SNOT-22, endoscopic scores and work days lost. Data was analyzed with SPSS version 22. Quantitative data was analyzed by calculating mean and standard deviation. Frequency and percentages were calculated for qualitative data. Chi-square test and independent $t$ test was applied. $P$ value $\leq 0.05$ was considered significant.

\section{RESULTS}

Total of 22 refractory CRS patients were included in study. There were $10(45.5 \%)$ male and $12(54.5 \%)$ female. Mean age of refractory CRS patients was 33.4 years $\pm 6.2 S D$. There were 16(72.7\%) patients in age group 19-35 years and $6(27.3 \%)$ patients in age group $>35$ years. Among all refractory CRS patients 22(100\%), 10(45.5\%) patients were smokers and $12(54.5 \%)$ were non smokers. Out of all, $11(50 \%)$ were asthmatic and $11(50 \%)$ were non asthmatic. There were $8(36.4 \%)$ patients with allergy while $14(63.6 \%)$ were non allergic. Nasal polyps were reported in 10(45.5\%) patients while $12(54.5 \%)$ did not have comorbidities like nasal polyps.

Group A (continued medical therapy) $N=11$, had significantly high SNOT -22 scores 60.6 $\pm 7.1 S D$ as compared to Group B 21 $23.9 S D(p=0.000)$.

Group B (endoscopic sinus surgery) had significantly low endoscopic scores $2.7 \pm 0.3 S D$ as compared to group $A$ (continued medical therapy) $7.14 \pm 0.53 S D(p=0.000)$. The endoscopic sinus surgery group showed significant reduction in work days lost $17.4 \pm 4.9 S D$ as compared to continued medical therapy group 30.1 $22.5 S D(p=0.000$ ( table 2).

Among all those patient in Group $A(n=11)$, majority of patients were in age group 19-35 years while in Group B $(n=11), 5(22.7 \%)$ were in age group $19-35$ years and $6(27.3 \%)$ were in age group $>35$ years $(p=0.01)$. In group $\mathrm{A}$, there were $7(31.8 \%)$ male and $4(18.2 \%)$ female patients while in group $\mathrm{B}, 3(13.6 \%)$ male and $8(36.4 \%)$ female $(p=0.196)$ (Table 3$)$. There were also insignificant association was found in both interventional groups and asthma $(p=0.39)$, allergy $(p=0.65)$, nasal polyps $(p=0.67)$ and smoking $(\mathrm{p}=0.67)$.

Most common 5 items mentioned on SNOT 22 scale were facial pain $45 \%$, thick nasal discharge $23 \%$, nasal obstruction $23 \%$, reduced concentration $4 \%$ and loss of smell and taste $5 \%$ as shown in figure 1.

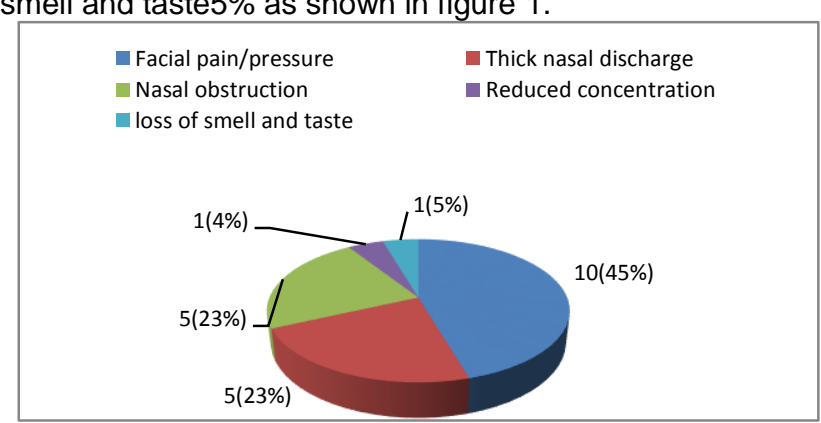

Figure 1: Most common items on SNOT 22 scale

Table 1: Comparison of disease specific quality of life through sinonasal outcome test 22

\begin{tabular}{|l|l|l|l|l|}
\hline Interventional groups & $\mathbf{n = 2 2}$ & Mean scores & Standard Deviation & P value \\
\hline Group A (Continued medical therapy) & 11 & 60.6 & 7.10 & 0.000 \\
\hline Group B (Endoscopic Sinus Surgery) & 11 & 21 & 3.9 & \\
\hline
\end{tabular}


Table 2: Comparison of secondary outcomes in interventional groups

\begin{tabular}{|c|c|c|c|c|}
\hline \multirow[t]{2}{*}{ Variables } & \multicolumn{2}{|c|}{ Interventional groups } & \multirow[t]{2}{*}{ T value } & \multirow[t]{2}{*}{$P$ value } \\
\hline & Group A (Continued medical therapy) & Group B (Endoscopic sinus surgery) & & \\
\hline Endoscopic scores & $7.14 \pm 0.53 S D$ & $2.7 \pm 0.3 S D$ & 23 & 0.000 \\
\hline Work days lost & $30.1 \pm 2.5 \mathrm{SD}$ & $17.4 \pm 4.9 S D$ & 7.6 & 0.000 \\
\hline
\end{tabular}

Table 3: Association between interventional group and independent variables

\begin{tabular}{|c|c|c|c|c|}
\hline \multirow[t]{2}{*}{ Age } & \multicolumn{2}{|c|}{ Interventional groups } & \multirow[t]{2}{*}{ Total } & \multirow[t]{2}{*}{$P$ value } \\
\hline & Group A (continued medical therapy) & Group B (Endoscopic Sinus Surgery) & & \\
\hline $19-35$ years & $11(50 \%)$ & $5(22.7 \%)$ & $16(72.7 \%)$ & \multirow[t]{2}{*}{0.01} \\
\hline$>35$ years & $0(0 \%)$ & $6(27.3 \%)$ & $6(27.3 \%)$ & \\
\hline \multicolumn{5}{|l|}{ Gender } \\
\hline Male & $7(31.8 \%)$ & $3(13.6 \%)$ & $10(45.5 \%)$ & \multirow[t]{2}{*}{0.198} \\
\hline Female & $4(18.2 \%)$ & $8(36.4 \%)$ & $12(54.5 \%)$ & \\
\hline Total & $11(50 \%)$ & $11(50 \%)$ & $22(100 \%)$ & \\
\hline
\end{tabular}

\section{DISCUSSION}

Refractory CRS has significant contribution in individual morbidity and quality of life deterioration. In current study total of 22 patients were included. Mean age of refractory CRS patients was 33.4 years $\pm 6.2 S D$. Majority of patients were in age group 19-35 years $72.7 \%$. Macdonald et al reported that mean age of CRS patients was 35 years $\pm 1.2 S D$ with cardiovascular diseases, obesity, asthma and diabetes mellitus as comorbidities ${ }^{13}$.

In the present study, Group A (continued medical therapy) $n=11$, had significantly high SNOT -22 scores $60.6 \pm 7.1 \mathrm{SD}$ as compare to endoscopic sinus surgery $21 \pm 3.9 S D(p=0.000)$. Bhattacharyya et al reported low SNOTT scores in endoscopic sinus surgery as compared to medical therapy (66 vs $16, p=0.001)^{14}$. However, Bezerra et al reported no significant difference in SNOTT scores in endoscopic surgery and medical therapy after 1 month (66 v2 $67, p=0.34)^{15}$.

In the present study, Group B (endoscopic sinus surgery) had significantly low endoscopic scores $2.7 \pm 0.3 S D$ as compared to group A (continued medical therapy) $7.14 \pm 0.53 S D(p=0.000)$. Ragab et al reported significant reduction in endoscopic scores in endoscopic sinus surgery in refractory CRS patients $(p=0.02)^{16}$. Moreover, Ragab et al reported that refractory CRS patient treated with medical treatment for more than 3 months had more than 50 scores on SNOTT-2017.

In present study, endoscopic sinus surgery group showed significant reduction in work days lost 17.4 $44.9 S D$ as compare to continued medical therapy. Khalil et al reported that CRS patients treated with medical therapy were more prone to lost work days as compare to treated with endoscopic sinus surgery (RR:1.2, 95\% C.1, $P=0.00)^{18}$. Akdis et al had similar finding with reduced work days lost in endoscopic sinus surgery and greater work days lost in continued medical treatment among refractory CRS patients (10 vs 20 days, $\mathrm{p}=0.05)^{19}$.

In the present study, most common five items mentioned on SNOT 22 scale were facial pain, thick nasal discharge, nasal obstruction, reduced concentration and loss of smell and taste5\%. Lam et al reported fatigue, sneezing, nasal obstruction, sad mood and waking up at night $23 \%, 20 \%, 10 \%, 2 \%$ and $1 \%$ respectively as most common item mentioned by participants on SNOTT 22 scale $^{20}$.
Limitation: Small sample size as a long list of endoscopic sinus surgery limits generalisability of study

\section{CONCLUSION}

Endoscopic sinus surgery is an effective treatment option as compared to continued medical therapy with improved quality of life in refractory CRS patients (with reduced baseline disease specific quality of life). There is a need to consider disease specific quality of life in decision making process for treatment of patients with refractory CRS in Pakistan.

\section{Conflict of interest: Nil}

\section{REFERENCES}

1. Soler ZM, Arih Al. Patient-centered decision making in the treatment of chronic rhinosinusitis. Laryngoscope. 2013; 123(10): 2341-6.

2. Smith TL, Asoq VI. Medical therapy vs surgery for chronic rhinosinusitis: a prospective, multi-institutional study. Int Forum Allergy Rhinol. 2011;1(4):235-41.

3. Smith KA, Rudmik L. Impact of continued medical therapy in patients with refractory chronic rhinosinusitis. Int Forum Allergy Rhinol. 2014;4(1):34-8.

4. Rosenfeld RM, Rasi R, Liu L. Clinical practice guideline on adult sinusitis. Otolaryngol Head Neck Surg. 2017;137(3):365-77

5. Soler ZM, Aonl M, Danum AS. Antimicrobials and chronic rhinosinusitis with or without polyposis in adults: an evidenced-based review with recommendations. Int Forum Allergy Rhinol. 2013;3(1):31-47.

6. Rudmik L, Topical therapies in the management of chronic rhinosinusitis: an evidence-based review with recommendations. Int Forum Allergy Rhinol. 2013;3(4):28198.

7. Poetker DM, Willum S, Azx Bo. Oral corticosteroids in the management of adult chronic rhinosinusitis with and without nasal polyps: an evidence-based review with recommendations. Int Forum Allergy Rhinol. 2013;3(2):10420.

8. Rudmik L, Queen M, Mobel Arm. Early postoperative care following endoscopic sinus surgery: an evidence-based review with recommendations. Int Forum Allergy Rhinol. 2015;1(6):417-30.

9. Hopkins C, Arosl Con, Aqua L. Psychometric validity of the 22-item Sinonasal Outcome Test. Clin Otolaryngol. 2014;34(5):447-54.

10. Lund VJ, Kennedy DW. Staging for rhinosinusitis. Otolaryngol Head Neck Surg. 1997;117(3 Pt 2):S35-40. 
11. Hopkins C, John H, Sunny K. The Lund-Mackay staging system for chronic rhinosinusitis: how is it used and what does it predict? Otolaryngol Head Neck Surg. 2014;137(4):555-61.

12. Smith TL, Elin C, Poket J.. Determinants of outcomes of sinus surgery: a multiinstitutional prospective cohort study. Otolaryngol Head Neck Surg. 2015;142(1):55-63.

13. Macdonald KI, McNally JD, Massoud E. Quality of life and impact of surgery on patients with chronic rhinosinusitis. $J$ Otolaryngol Head Neck Surg. 2014;38(2):286-93.

14. Bhattacharyya N. Clinical outcomes after endoscopic sinus surgery. Curr Opin Allergy Clin Immunol. 2016;6(3):167-71.

15. Bezerra TF, Jack V, Efron M. Assessment of quality of life after endoscopic sinus surgery for chronic rhinosinusitis. Braz J Otorhinolaryngol. 2015;78(2):96-102.

16. Ragab SM, Ashmid S, Akram A. Impact of chronic rhinosinusitis therapy on quality of life: a prospective randomized controlled trial. Rhinology. 2016;48(3):305-11.
17. Ragab SM, Lund VJ, Scadding G. Evaluation of the medical and surgical treatment of chronic rhinosinusitis: a prospective, randomised, controlled trial. Laryngoscope. 2018;114(5):92330.

18. Khalil HS, Nunez DA. Functional endoscopic sinus surgery for chronic rhinosinusitis. Cochrane Database Syst Rev. 2016;(3):44-58.

19. Akdis CA, Sea L, Jab D. Endotypes and phenotypes of chronic rhinosinusitis: a PRACTALL document of the European Academy of Allergy and Clinical Immunology and the American Academy of Allergy, Asthma \&amp; Immunology. J Allergy Clin Immunol. 2015;131(6):1479-90.

20. Lam M, Merry $Q$, Zech A. Clinical severity and epithelial endotypes in chronic rhinosinusitis. Int Forum Allergy Rhinol. 2015;3(2):121-8. 